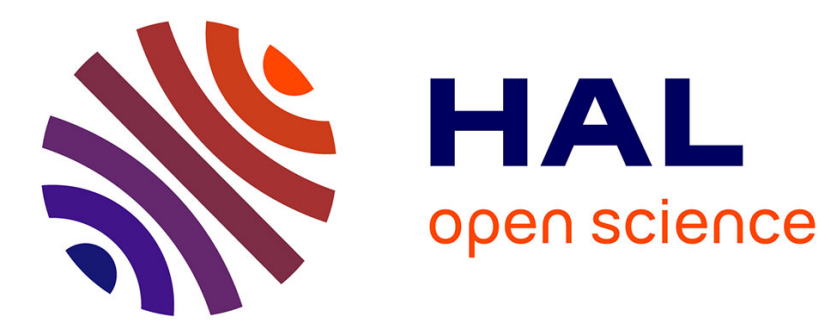

\title{
Coronary angiography with synchrotron radiation
} W.-R. Dix, H. Besch, W. Graeff, C. Hamm, G. Illing, W. Kupper, M. Lohmann, T. Meinertz, R. Menk, B. Reime, et al.

\section{To cite this version:}

W.-R. Dix, H. Besch, W. Graeff, C. Hamm, G. Illing, et al.. Coronary angiography with synchrotron radiation. Journal de Physique IV Proceedings, 1994, 04 (C9), pp.C9-279-C9-286. 10.1051/jp4:1994949 . jpa-00253510

\section{HAL Id: jpa-00253510 https://hal.science/jpa-00253510}

Submitted on 1 Jan 1994

HAL is a multi-disciplinary open access archive for the deposit and dissemination of scientific research documents, whether they are published or not. The documents may come from teaching and research institutions in France or abroad, or from public or private research centers.
L'archive ouverte pluridisciplinaire HAL, est destinée au dépôt et à la diffusion de documents scientifiques de niveau recherche, publiés ou non, émanant des établissements d'enseignement et de recherche français ou étrangers, des laboratoires publics ou privés. 


\section{Coronary angiography with synchrotron radiation}

W.-R. Dix, H.J. Besch*, W. Graeff, C.W. Hamm**, G. Illing, W. Kupper***, M. Lohmann*, T. Meinertz**, R.H. Menk, B. Reime, C. Rust**, L. Schildwächter, U. Tafelmeier and A.H. Walenta*

Hamburger Synchrotron-Strahlungslabor, HASYLAB at DESY, Notkestr. 85, 22607 Hamburg, Germany

* Fachbereich 7 Physik der Universität Gesamthochschule Siegen, Adolf-Reichwein-Str. 2, 57068 Siegen, Germany

** Kardiologische Abteilung der Medizinischen Klinik, Universitäts-Krankenhaus Eppendorf, Martinistr. 52, 20251 Hamburg, Germany

*** Herz-Kreislauf-Klinik, Römstedter Str. 25, 29549 Bad Bevensen, Germany

Worldwide several systems for Digital Subtraction Angiography in energy subtraction mode (dichromography) are developed. One of the systems which allows investigations of patients - the system NIKOS in the Hamburger Synchrotronstrahlungslabor HASYLAB at DESY is described. The system consists out of six main parts: The 20 pole wiggler $\mathrm{HARWI}$ in the beamline $\mathrm{W} 2$ of the storage ring DORIS, the two beam monochromator for the two $12.5 \mathrm{~cm}$ wide monochromatic X-ray beams, the safety system, the fast scanning device, the fast low-noise two-line ionization chamber and the computer system.

Since 1990 patients were investigated with the system NIKOS. Aim of the work is to risualize coronary arteries down to $1 \mathrm{~mm}$ diameter with an iodine mass, density of $1 \mathrm{mg} / \mathrm{cm}^{2}$, thus allowing non-invasive investigations by intravenous application of the contrast medium. The two images for subtraction are simultaneously taken with photon energies just below and above the iodine $\mathrm{K}$-edge $(33.17 \mathrm{keV})$ in a line scan mode.

Intravenous angiograms from investigations with version III of the system NIKOS are presented and the next steps for getting an increased image quality are described.

\section{Introduction}

Today in most of the synchrotron radiation facilitjes worldwide systems for medical applications like multiple energy computed tomography, micro beam radiation therapy, mammography and intravenous coronary angiography are under development. The most advanced application of synchrotron radiation for medical purposes is intravenous coronary angiography on the base of digital subtraction angiography (DSA) in energy subtraction mode (dichromography). Systems for dichromography are under development at the NSLS in Brookhaven, USA ${ }^{(1)}$ (before at SSRL in Stanford, USA ${ }^{(2)}$ ), at VEPP in Novosibirsk, Russia ${ }^{(3)}$, at HASYLAB in Hamburg, Germany ${ }^{(4)}$, at the Photon Factory in Tsukuba. Japan ${ }^{(5,6)}$ and at the ESRF in Grenoble, France ${ }^{(7)}$. Only two of these systems - the system at the NSLS and the system NIKOS at HASYLAB - currently allow the investigation of patients. Both are line scan systems, the setups are very similar in principle, and the quality of the resulting images is comparable. Therefore, in this paper only the system NIKOS is described in detail. The system NIKOS is installed in the beamline W2 of the storage ring DORIS at the Hamburger Synchrotronstrahlungslabor HASYLAB at DESY in Hamburg.

Dichromography eliminates the need for arterial catheterization of the coronary arteries thus diminishing the risks to the patient. The aim of the work is to visualize coronary arteries as small as $1 \mathrm{~mm}$ in diameter with an iodine mass density of $1 \mathrm{mg} / \mathrm{cm}^{2}$, following intravenous injection of the 
contrast agent. In conventional DSA, normally used for intravenous investigations, the images with different iodine contrast are taken at different times. This time subtraction mode is not suitable for the imaging of small coronary arteries because of the fast motion of the heart. For the dichromography the two images for subtraction are simultaneously taken with photon energies just below and above the jodine K-edge (33.17 keV). This results in two images with different iodine contrast and almost no differences for bone and soft tissue. The method is 10000 times more sensitive to iodine than to soft tissue what allows the imaging of structures with very low mass density of iodine.

The system NIKOS was developed since 1981. In 1990 human studies began. The quality of the first images was not suited for clinical routine evaluations. Meanwhile a remarkable increase of image quality was achieved especially since the installation of version III of the system NIKOS mid of 1993. This version of the system is described in section 2. Examples of the images are given in section 3 followed by an outlook in section 4 .

\section{The NIKOS III system}

Because NIKOS is a line scan system the background signals from scattered radiation are reduced remarkably. The system performance parameters for intravenous contrast medium injections within $250 \mathrm{~ms}$, in a field of $12.5 \times 12.5 \mathrm{~cm}^{2}$, are given in ref. (8). The version III of the NIKOS system consists out of six main components (Fig.1).

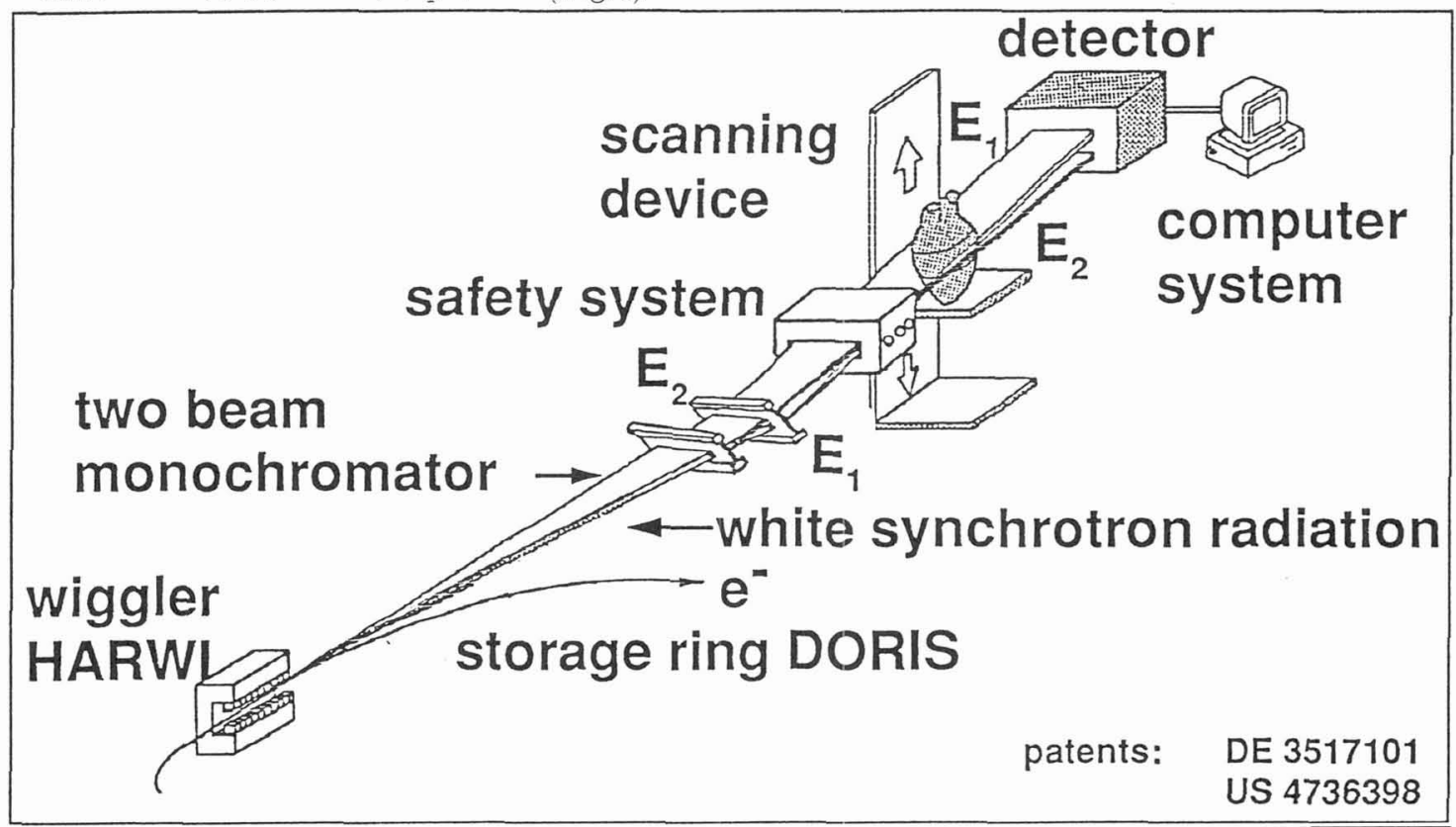

Figure 1: Scheme of the experimental setup

- The 20 pole wiggler HARWI ${ }^{(9)}$ has a length of $2.4 \mathrm{~m}$ plus $0.12 \mathrm{~m}$ for the endpoles. After installation of a variable vacuum chamber the minimal magnetic gap is $30 \mathrm{~mm}$ high and the maximum field strength amounts to $1.26 \mathrm{~T}$. During the investigation of the patients DORIS operated at an energy of $4.5 \mathrm{GeV}$ ( 2 or 5 bunches), with a current of about $50 \mathrm{~mA}$. For these conditions the critical energy is $17.0 \mathrm{keV}$ and the horizontal opening angle is 6.4 mrad.

- The two monochromatic x-ray beams are diffracted out of the white synchrotron radiation beam by the monochromator. A $0.6 \mathrm{~mm}$ thick, $11 \mathrm{~mm}$ high and $112 \mathrm{~mm}$ wide $\mathrm{Si}(111)$ crystal is installed in Laue geometry for each monochromatic beam. Following an idea in ref. (10) 
the crystals are bent with a radius of $11 \mathrm{~m}$ in order to focus the beam thus increasing the flux at the patient. The flux was measured to be $0.8 \cdot 10^{11}$ photons $/\left(\mathrm{mm}^{2} \cdot \mathrm{s}\right)$ for $50 \mathrm{~mA}$ current in DORIS. This is an increase of a factor 6 compared to the former monochromator with two $\mathrm{Ge}(111)$ crystals in Bragg geometry. The crystals are cut asymmetrically (asymmetry angle $\left.35.26^{\circ}\right)$. They are installed in a He-filled tube and cooled by water. The height of the beams is $1.7 \mathrm{~mm}$ at the monochromator, $0.6 \mathrm{~mm}$ at the patient and $0.9 \mathrm{~mm}$ at the detector. The bandwidth of the monochromatic beams is $180 \mathrm{eV}$, the energy separation $300 \mathrm{eV}$.

- A redundant safety system with three independent shutters switches off the monochromatic beams within less than $10 \mathrm{~ms}$ in case of any system failure.

- The fast scanning device can move loads of up to $300 \mathrm{~kg}$ over a distance of $20 \mathrm{~cm}$ with constant speed up to $50 \mathrm{~cm} / \mathrm{s}$ (precision $1 \%$ ). During the human study runs the scanning device ran with $12 \mathrm{~cm} / \mathrm{s}$ to $23 \mathrm{~cm} / \mathrm{s}$. Its moving force is generated by a hydraulic system. It is equiped with a chair for the patient. The chair allows for a patient rotation of $\pm 180^{\circ}$ about the vertical axis and $\pm 20^{\circ}$ about the lateral axis in order to set the appropriate projection angles. During the vertical scan of the patient a precise optical scale triggers the readout of the detector every $0.5 \mathrm{~mm}$ (August 1993) or $0.4 \mathrm{~mm}$ (November 1993), respectively. Thus the vertical pixel size in the images is defined.

- As a detector a fast low-noise two-line ionization chamber ${ }^{(11)}$ is installed which simultaneously records the two lines with the energy above and below the K-edge, respectively. It has a common drift cathode and for each line a Frisch grid and $256 \mathrm{Cu}$-strips as anodes. The $17 \mu \mathrm{m}$ thick and $55 \mathrm{~mm}$ long $\mathrm{Cu}$-strips are directed along the monochromatic beams. The center-tocenter distance of the strips is $0.4 \mathrm{~mm}$ thus defining the horizontal pixel size in the images. The chamber is filled with $90 \%$ of $\mathrm{Kr}$ gas and $10 \%$ of $\mathrm{CO}_{2}$ under 14 bar pressure. The $0.5 \mathrm{~mm}$ thick entrance window is made of carbon fiber imbedded in polyimide matrix. In front of it a collimator with two slits of $1.8 \mathrm{~mm}$ vertical height each and a center-to-center distance of $2.8 \mathrm{~mm}$ is mounted.

The ionization current of each strip is summed up in resettable integrators whose output is transferred in parallel into sample-and-hold registers and afterwards digitized with one 16bit ADC (Analogic DVX 2503) per line. The readout time per line is $2 \mathrm{~ms}$. The data are transmitted to the computer via two glass fiber links with a maximal transfer rate of $4.4 \mathrm{Mbaud}$. The dynamic range of the complete detector system was measured to be $40000: 1$. The detecting quantum efficiency of the complete system

$$
\mathrm{DQE}=\frac{\left(S N R_{\text {OUT }}\right)^{2}}{\left(S N R_{I N}\right)^{2}}
$$

$\left(\mathrm{SNR}_{\text {OUT }}=\right.$ signal-noise-ratio in the images, $\mathrm{SNR}_{I N}=$ signal-noise-ratio in front of the detector; $\left(S N R_{I N}\right)^{2}=N_{\gamma}=$ number of photons per pixel) was determined to be DQE $=58 \%$ for $33 \mathrm{keV}$ photons.

- The computer system consists of a VAX station 3500 for the coordination of the computer system, for data acquisition, image processing and presentation and a PDP 11/73 for control of the system. The two machines are linked via a serial line and connected to the DESY computer center (IBM ES 9000/720 VF). In the center the data are stored in a data base (DB2). 


\section{Results of human studies}

During 1993 after installation of the NIKOS III system seven patients were studied in two different periods. Each investigation started with a positioning run with reduced skin dose $(15 \mathrm{mGy}$ in a field of $\left.10.1 \times 12.8 \mathrm{~cm}^{2}\right)$, reduced amount of contrast agent $(10 \mathrm{ml}$ or $20 \mathrm{ml}$ injected with $15 \mathrm{ml} / \mathrm{s}$ or $20 \mathrm{ml} / \mathrm{s}$ ) and only one scan. After correction of the position of the patient the investigation run with two scans each was started.

It is difficult and in some cases impossible to distinguish between coronary arteries and pulmonary veins if only one image per injection of contrast material exists. Identification of these vessels is much easier if a sequence of images is recorded because the contrast material enters and leaves these vessels at different times. On the other hand it is not possible to take a long sequence of images after the injection of the contrast material because of the skin dose per image. Therefore, as a compromise, two images per injection were recorded. In consequence that means that the scan of the patient must be started at the optimal time. A study ${ }^{(12)}$ has shown that the circulation times of different patients can vary from 6.8 to $24.6 \mathrm{~s}$. The values depend on the pulse rate of the patient and the cardiac output, which can in some cases change dramatically during the imaging procedure. These changing circulation times can influence the quality of the images because the time interval for optimal images is small. The images must be taken about $1 \mathrm{~s}$ after the arrival of the contrast agent in the coronary arteries. Two seconds later the image quality is no longer satisfactory. Therefore, we measured the circulation time of the patient with a dye just before the investigation run starts. For this purpose $5 \mathrm{ml}$ of Cardio Green are injected via the same catheter as used for the contrast agent. With the use of a sensor at the patient's ear and a densitometer the time between injection of the solution and its arrival in the ear is determined. This procedure has allowed the scan to be recorded at the optimal time in about $70 \%$ of the cases. More experience with this method will improve this result.

For the investigation the speed of the scanning device was adjusted relative to the measured flux in the monochromatic beams in a way that the skin dose per scan to the patient in the small field (see above) was $50 \mathrm{mGy}$. The speed varies betwenn $9.2 \mathrm{~cm} / \mathrm{s}$ and $22.0 \mathrm{~cm} / \mathrm{s}$. The time interval between the images was 1.7 to $2.2 \mathrm{~s}$ (depending on the scan speed).

Depending on the coronary artery of interest the patients were investigated in different projections: $\mathrm{LAO} 20^{\circ}$, $\mathrm{LAO} 30^{\circ}$, $\mathrm{LAO} 40^{\circ}$, RAO $30^{\circ}\left(\mathrm{CCO}^{\circ}\right.$ or $\left.\mathrm{CC} 10^{\circ}\right)$ or left lateral. For the investigation runs $30 \mathrm{ml}$ of contrast agent (Solutrast ${ }^{\circ}, 370 \mathrm{mg}$ of iodine per $\mathrm{ml}$ ) were injected within $2 \mathrm{~s}$ into the superior vena cava This intravenous injection was performed via a $i \mathrm{~F}$ pigtail catheter.

Fig.2 shows the energy images of a patient in a $\mathrm{LAO} 30^{\circ}$-projection. The resulting subtraction image is shown in Fig. 3 together with the second image of the same contrast agent injection. For comparison Fig.4 shows the same patient in a slightly different projection (LAO $40^{\circ}$-projection). In this case not only the right coronary artery (RCA) is visible but also part of the left anterior descending coronary artery (LAD). This demonstrates that carefully selected projections together with a wider detector could allow the visualization of left and right coronary arteries in the same image. Therefore, for the investigations in 1994 a $12.5 \mathrm{~cm}$ wide version of the two-line jonization chamber will be installed.

Fig.5 shows the two images of another patient in RAO $30^{\circ}$-projection. The LAD is clearly visible but the circumflex coronary artery $(\mathrm{Cx})$ is superposed by the left ventricle (LV) and therefore not visible. This is in agreement with a study ${ }^{(13)}$ which showed that the visualization of the RCA should be possible in any cases. The LAD should be visible without superposition of large structures like $\mathrm{LV}$, left atrium (LA) or aorta (Ao) in $80 \%$ of the cases. Problems are expected with the main stem and the $\mathrm{Cx}$.

Because it is essential for the method that all coronary arteries can be imaged, image processing methods must be used to visualize those parts of the coronary arteries which are superposed by large structures. Therefore, the right images in Figs. 3 and 5 were processed with an unsharp masking algorithm. The preliminary results are shown in Fig.6. The superposed parts are visible but the quality of these images must be increased by more sophisticated algorithms. 


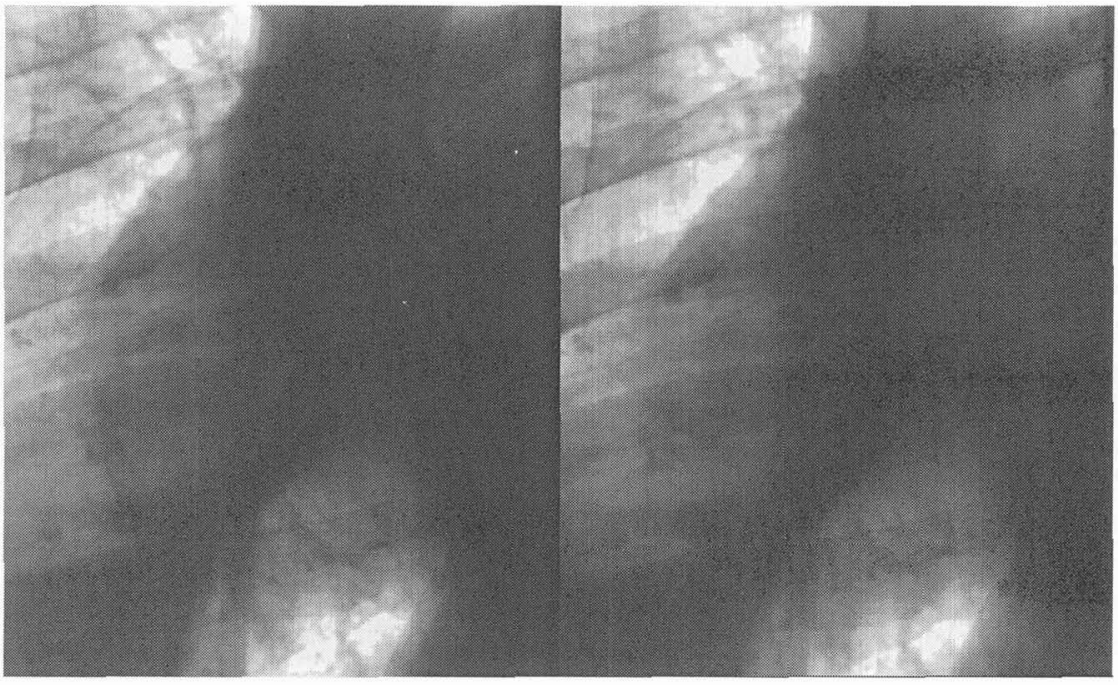

Figure 2: Energy images of a 65 year old man $(65 \mathrm{~kg})$ in LAO30 -projection from November 1993. The scan speed was $16.0 \mathrm{~cm} / \mathrm{s}$. The pixel size was $0.4 \times 0.4 \mathrm{~mm}^{2}$. The DORIS storage ring ran with a current of $64 \mathrm{~mA}$. $30 \mathrm{ml}$ of contrast agent were injected via a $i F$ pigtail catheter into the superior vena cava within $2 \mathrm{~s}$. Left side: image with energy above the K-edge of iodine, right side: energy below the K-edge. The subtraction image is shown in Fig.3 (left side).

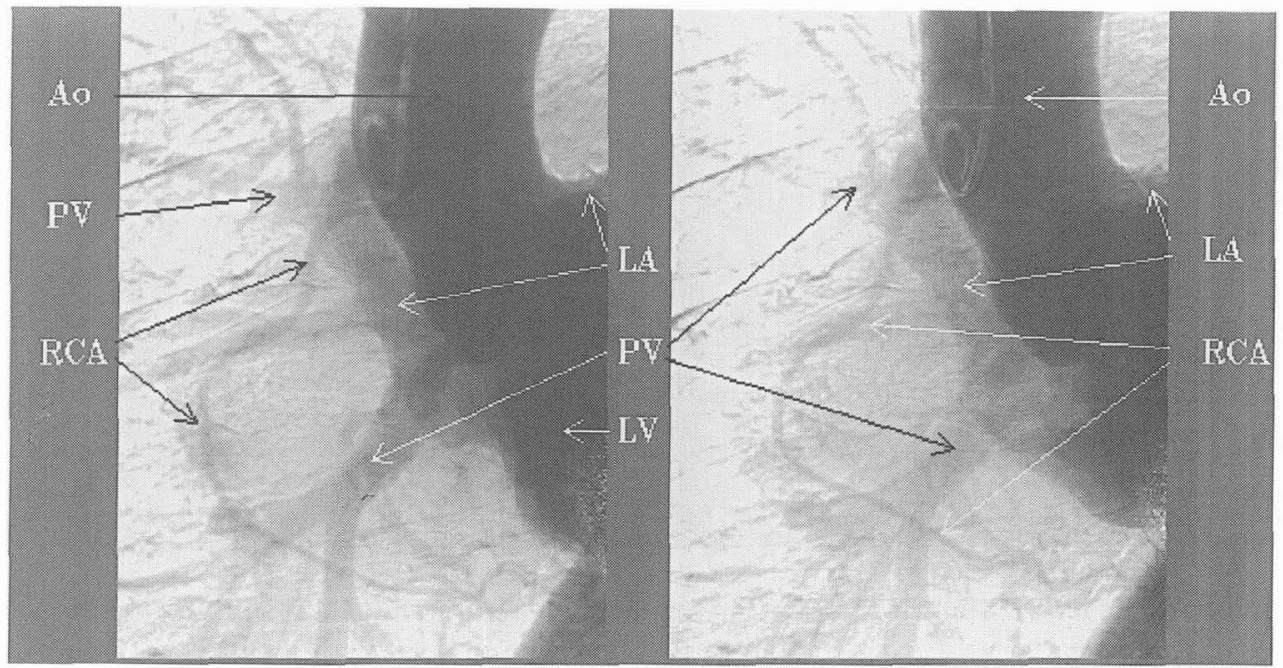

Figure 3: Intravenous angiograms of the same run. The first scan (left side) was started $14.6 \mathrm{~s}$ after injection of the contrast agent; the second scan (right side) was started $16.3 \mathrm{~s}$ after injection. The second scan was optimized for the measured circulation time. Visible are right coronary artery (RCA), parts of the aorta (Ao), of the left atrium (LA), of the left ventricle (LV) and pulmonary veins $(P V)$. 


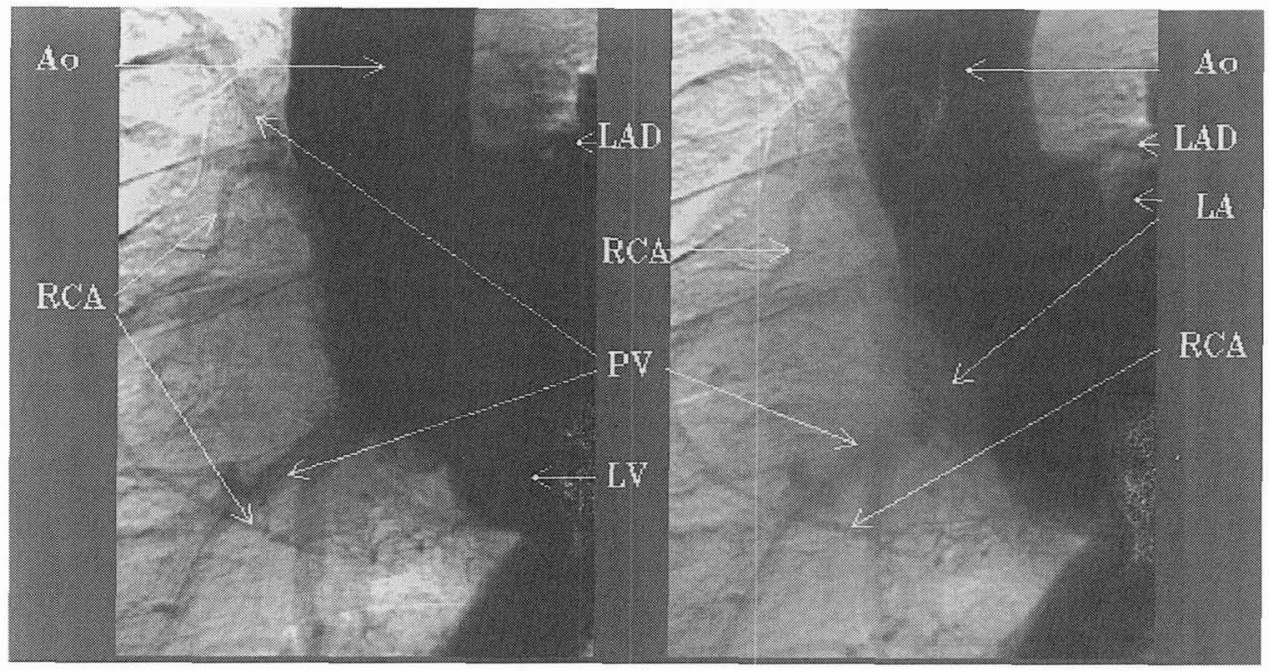

Figure 4: Intravenous angiograms of the same patient as in Fig. 3 in LAO40 $40^{\circ}$-projection. The parameters are the same as in Fig. 3 with the following exceptions: The scan speed was $12.5 \mathrm{~cm} / \mathrm{s}$. The DORIS storage ring ran with a current of $49 \mathrm{~mA}$. Visible are right coronary artery (RCA), parts of the aorta (Ao), of the left atrium (LA), of the left ventricle (LV), pulmonary veins (PV) and additional part of the left anterior descending coronary artery (LAD).

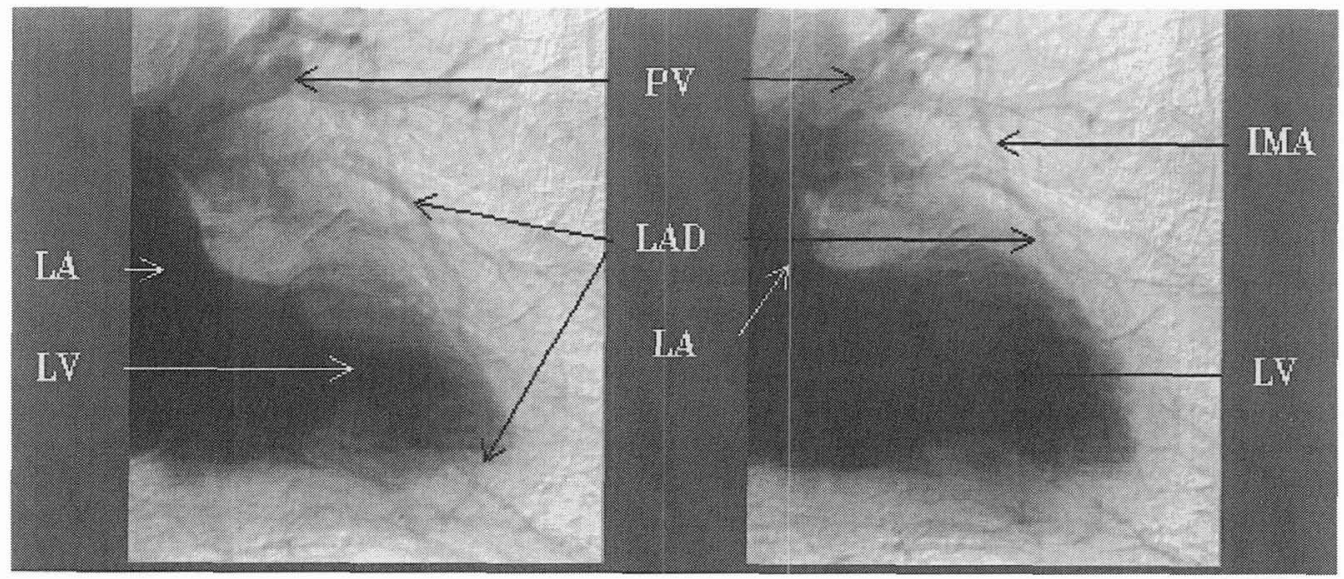

Figure 5: Intravenous angiograms of a 56 year old man $(91 \mathrm{~kg})$ in RAO30 1993. The scan speed was $16.7 \mathrm{~cm} / \mathrm{s}$. The DORIS storage ring ran with a current of $51 \mathrm{~mA} .30 \mathrm{ml}$ of contrast agent were injected via a $6 \mathrm{~F}$ pigtail catheter into the superior vena cava within $2 \mathrm{~s}$. The first scan (left side) was started $16.0 \mathrm{~s}$ after injection of the contrast agent; the second scan (right side) was started $17.7 \mathrm{~s}$ after injection. The second scan was optimized for the measured circulation time. Visible are left anterior descending coronary artery (LAD), parts of the left atrium (LA), of the left ventricle (LV), of the internal mammary artery (IMA) and pulmonary veins (PV). 


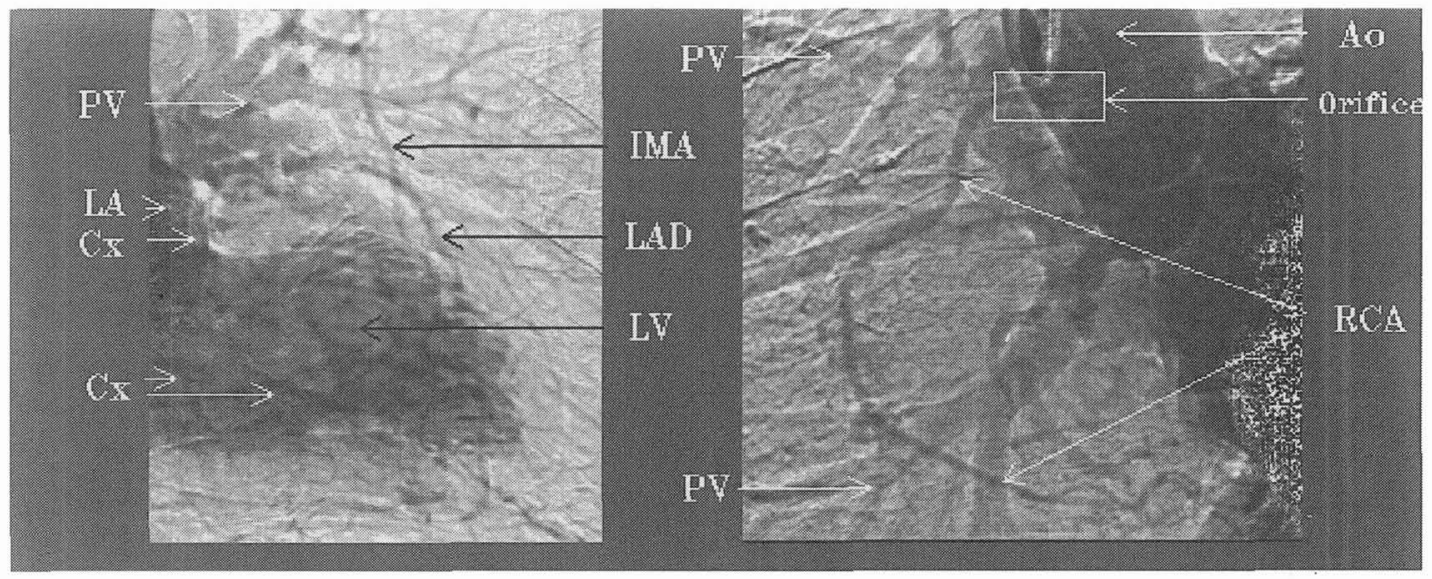

Figure 6: Intravenous angiograms from Fig.5 (right side) and Fig.3 (left side) after image processing with an unsharp masking technique. Visible are the $\mathrm{Cx}$ inclusive bifurcation (left side) and the orifice of the RCA (right side).

\section{Outlook}

A further increase of image quality without increase of skin dose is of great interest. Therefore, changes and developments in several directions were started.

A new more stable version of the monochromater will be installed before the next investigations. An increase in the flux of $20 \%$ is expected. The update of the storage ring DORIS ( $e^{+}$instead of $e^{-}$) should result in a higher current in the machine and longer storage times. Together with the installation of an advanced beam position control in the beamline the aimed flux of $3 \times 10^{11}$ photons $/ \mathrm{mm}^{2} / \mathrm{s}$ in the monochromatic beams in front of the patient is possible. The increased flux makes it possible to scan at $50 \mathrm{~cm} / \mathrm{s}$. This provides the opportunity to take the images in the slow motion phase of the heart, thus decreasing the blurring of the images due to cardiac motion of the heart. Furthermore the vertical smearing from the line scan will be reduced.

The installation of the new version of the detector not only increases the horizontal width of the images to $13.4 \mathrm{~cm}$ but also increases the dynamic range to $60000: 1$ and decreases the readout time per line to 1 ms. Tests müst show whether the DQE can be increased from $58 \%$ today to the theoretical value of $80 \%$. The improved parameters will increase the signal to noise ratio in the images.

The image processing work must be intensified. With new algorithms for edge preserving smoothing, corrections for higher harmonics in the monochromatic beams, system dependent corrections etc. a higher image quality must be achieved.

Furthermore the medical parameters for the investigations of patients without substantial loss of image quality will be optimized within the next two years. In detail the following parameters must be determined:

- The best projections for imaging of all coronary arteries,

- the best suited phase of the heart cycle for the images,

- the minimal amount of contrast agent,

- the maximal speed for injection of contrast medium,

- injection into the antecubital vein instead of the superior vena cava,

- optimal scan time relative to measured circulation time,

- minimal skin dose.

In a second phase the dichromography will be validated against selective coronary angiography. 
At the same time e.g. basic research on natural history of coronary artery disease and the study of effects of therapeutic interventions will be possible.

The angiography program and ist technology are now based at beamlines in synchrotron radiation laboratories. In order for the technology to become widespread, and therefore of greater value to the general population, compact sources of $x$-rays with sufficient flux coupled with the necessary digital subtraction imaging system must be developed. First concepts for such low cost $\mathrm{x}$-ray sources are presented in Japan and the USA.

\section{Acknowledgements}

The authors wish to thank J.Knabe and R. Wengler for assistance during the human study runs. We also like to thank H.W.Schenk for fruitful discussions and useful comments on the developement of the two-line ionization chamber. The first tests of the monochromator were performed at beamline ID11 of the ESRF. The assistance of A.Kwik, C.Schulze and P.Suortti is gratefully acknowledged.

\section{References}

(1) Thomlinson W., Gmür N., Chapman D., Garett R., Lazarz N., Zeman H.D., Brown G.S., Morrison J., Reiser P., Padmanabhan V., Ong L., Green S., Giacomini J., Gordon H. and Rubenstein E., Rev.Sci.Instr.63 (1992) 625-628.

(2) Rubenstein E., Giacomini J.C., Gordon H.J., Thompson A.C., Brown G., Hofstadter R.. Thomlinson W. and Zeman H.D., NIMPR A291 (1990) 80-85.

(3) Dolbnya I.P., Kulipanow G.N., Kurylo S.G., Mezentsev N.A., Pindyurin V.F. and Sheromov M.A., Phys.Med. Vol.VI N.3-4 (1990) 313-317.

(4) Dix W.-R., Engelke K., Graeff W., Hamm C., Heuer J., Kaempf B., Kupper W., Lohmann M., Reime B. and Reumann R., NIMPR A314 (1992) 307-315.

(5) Hyodo K., Nishimura K. and Ando M., Handbook on Synchrotron Radiation Vol.4 (Elsevier Science Publishers B.V., Amsterdam, 1991) pp. 55-94.

(6) Umetani K., Ueda K., Takeda T., Anno I., Itai Y, Akisada M. and Nakajima T., Rev.Sci.Instr.63 (1992) 629-631.

( 7 ) Elleaume H., 'Description technique de la ligne médicale de 1:ESRF', Les applications du Rayonnement Synchrotron en recherche médicale, Workshop at the ESRF, Grenoble 4 February 1994. pp. 1/9-9/9.

(8) Graeff W. and Dix W.-R., Handbook on Synchrotron Radiation Vol.4 (Elsevier Science Publishers B.V., Amsterdam, 1991) pp. 407-430.

(9) Graeff W., Bittner L., Brefeld W., Hahn U., Heintze G., Heuer J., Kouptsidis J., Pflüger J., Schwartz M., Weiner E.W. and Wroblewski T., Rev.Sci.Instr.60 (1989) 1457-1459.

(10) Suortti P. and Thomlinson W., NIMPR A269 (1989) 639-648.

(11) Besch H.J., Dix W.-R., Großmann U., Heuer J., Langer R., Lohmann M., Menk R.H., Schenk H.W., Tafelmeier U., Wagener M., Walenta A.H. and Xu H.C., Phys.Medica Vol.IX,N.2-3 (1993) 171-174.

(12) Rust C., 'Vergleichende U'ntersuchungen über photodensitometrische Kreislaufbestimmung vor intravenöser Koronarangiographie mit Synchrotronstrahlung', Thesis, University of Hamburg, FRG (to be published).

(13) Kupper W., Dix W.-R., Graeff W., Steiner P., Engelke K., Glüer C.C. and Bleifeld W., 'Projection angles for intravenous coronary angiography', Synchrotron Radiation Applications to Digital Subtraction Angiography (SYRDA), Frascati 6-8 May 1987 (Società Italiana di Fisica, 1988) pp. 165-170. 